\title{
PREDICTING INDIANA PUBLIC MIDDLE SCHOOL SCIENCE ACHIEVEMENT BY SCHOOL DEMOGRAPHICS
}

\author{
Zafer Ozen, Ph.D. Student, Purdue University, zozen@purdue.edu \\ Nielsen Pereira, Associate Professor, Purdue University, npereira@purdue.edu
}

\begin{abstract}
Understanding school and student demographics is valuable to predict outcomes, especially student academic achievement. In this study, we investigated how school attendance, non-minority student rate, and school socioeconomic status (SES) predict a school's science average achievement.

\section{Brief Report}

We used 2019 Indiana Learning Evaluation Assessment Readiness Network (ILEARN; 2019) data regularly collected by the Indiana Department of Education and publicly available. For calculating socioeconomic status (SES) for each school, we used a conversion: one minus school's free/reduced lunch rate since free/reduced lunch rate is widely used to indicate school SES (e.g., Sirin, 2005). While calculating the school's science average achievement rates, we considered the rate of the students at and above proficiency in each school. The non-minority student rate represented White student rate in each school. Correlational statistics and multiple linear regression were implemented for 1,492 schools. All correlations between school average, science achievement, and other variables were significant $(p<.01)$. The correlation between school SES and school science average achievement was the highest $(r=.80)$. The correlation between school average science achievement and non-minority student rate was .65, and its correlation with school attendance rate was .58. We found that all predictors explained $70 \%$ of the variance $\left(R^{2}=.70, R_{\text {adjusted }}^{2}=.70, F(3,1488)=1157.14, p<.001\right)$. The largest effect belonged to school $\operatorname{SES}(\beta=.58, p<.001)$. The second-largest effect came from the non-minority student rate $(\beta=.22, p<$ $.001)$, while the smallest effect belonged to the school attendance rate $(\beta=.17, p<.001)$. School's predicted science average achievement is equal to $-2.07+.48($ School SES $)+.15$ (School non-minority rate $)+2.30$ (School attendance rate) .
\end{abstract}

According to Buckingham et al. (2013), students from low-income families are less likely to have a good supportive family atmosphere to develop children's fundamental skills, such as reading. In a metaanalytic review of research, Sirin (2005) found that the average correlation between school SES and academic achievement was .30 for 6,871 schools. Correlation estimates in this study are generally higher than those found in the existing literature. Considering the high $R^{2}$ value $\left(R^{2}=.70\right)$, this model explained the schools' science achievement well with the following three independent variables: school SES, school attendance, and school non-minority student rate. Explaining schools' science average achievement with that much closely fitted regression line might indicate some potential systematic problems in the Indiana education system, such as low instruction quality and low supportive classroom atmosphere in the schools with high free/reduced lunch rate. This result might also show that there is a need for further investigation. Conducting multi-level modeling with the data in three different levels (student, school, and school corporation levels) has the potential to provide more information about the relationship among the variables.

\section{References}

Buckingham, J., Wheldall, K., \& Beaman-Wheldall, R. (2013). Why poor children are more likely to become poor readers: The school years. Australian Journal of Education, 57, 190-213. doi:10.1177/0004944113495500

Indiana Learning Evaluation Readiness Network (ILEARN), (2019). Volume 1 Annual Technical Report. https://www.doe.in.gov/sites/default/files/assessment/ilearn-technical-report-2018-2019.pdf

Sirin, S. R. (2005). Socioeconomic status and academic achievement: A meta-analytic review of research. Review of Educational Research, 75, 417-453. 